\title{
GAAR: Gross Anatomy using Augmented Reality Mobile Application
}

\author{
Wan Aezwani Wan Abu Bakar ${ }^{1}$, Mohd Airil Solehan ${ }^{3}$ \\ Faculty of Informatics and Computing \\ Universiti Sultan Zainal Abidin (UniSZA) \\ Besut Campus, 22200 Besut, Terengganu, Malaysia
}

\author{
Mustafa Man², Ily Amalina Ahmad Sabri ${ }^{4}$ \\ Faculty of Ocean Engineering Technology and Informatics \\ Universiti Malaysia Terengganu (UMT) \\ 21030 Kuala Nerus, Terengganu, Malaysia
}

\begin{abstract}
Covid-19 pandemic has forced the teaching and learning activity into real time and real-world education meetings. The traditional physical and face-to-face meetings are avoided in accordance to reducing the close physical contacts among individuals. Thus, a new paradigm shift towards teaching and learning needs to be highly enforced. Teaching and learning on medical field especially require for real world anatomy against human or living things body. In response to providing the facility for medical teachers and learners, Gross Anatomy Augmented Reality (GAAR) is introduced. GAAR is an android mobile Augmented Reality (AR) learning tool to assist the educators and learners in internalizing 3D human anatomy with more fun and interactivity. The AR methodology is implied to attract the personal impacts and feelings towards operating of close to 'real' organ during anatomy practices. Traditional learning methods are changed with AR technology through small digital device. This application may be able to show the students the actual form of human gross anatomy and assist the teachers or educators' in explaining the sciences behind human body in more interactive and interesting. Furthermore, this application uses a 3-dimensional object, video and interactive info so that students are interested in using this application. The AR for education and learning is vital in bridging the digital divide among all generations through the conversion of static pictures into real-like 3D animation. The implementation results show that, through the real visualization, small to adult learners can imitate the real truth on human organ and how this can motivate them to take care of their bodies that would lead to a healthier living styles as well as easy memorizing of the subject contents.
\end{abstract}

Keywords-Augmented reality; gross anatomy; learning tool; android mobile application; 3D human anatomy

\section{INTRODUCTION}

Augmented reality (AR) is a technology of putting the static object into real and dynamic object. In AR, each object is enhanced to become a real physical world that is achieved through the use of digital visual elements, sound, or other sensory stimuli. The augmented technology aims to be an alternative method for educators and learners that offer for interactivity as compared to traditional methods. In response to Covid19 pandemic where the education and learning is conducted through virtual, the education sectors especially is facing greatest challenge in delivering the contents of any subject matters to all learners and key persons. Thus, some domain fields such as engineering, medical, pure sciences that requires total theory and practice are in demand for the technology that could build for a full interest among educators and learners.

Hence, Gross Anatomy Augmented Reality (GAAR) is developed as a touch-up and a complimentary tool as a combination of gross anatomy study into augmented reality (or close to reality) during early education level. This mobile AR application aims to enhance teacher's ability to educate students, drives their interest and help them to internalize through visual implicitly in the field of science and human anatomy. The environment of first, learning the theory, second make it visualize in real into their small and handy gadgets (i.e. smartphone device) could assist the implementation of GAAR to be run at all school.

The ultimate objective of this project is to design an application that include 3D models of anatomy such as liver, heart, kidney, stomach and skeleton system that have been developed during creation of mobile application environment combined with AR for the study of basic human anatomy. To achieve this objective, the following purpose hypothesis are tested: The development of GAAR mobile application specific purpose is for the field of human anatomy in three dimension (3D) in combination of AR is feasible and achievable, in order to be used as an educational tool for the student in primary and secondary schools. This acts as an alternative or replacement of a traditional teaching method and a description course on human anatomy.

Prior to the development of a good working prototype of the application, the next hypothesis is it usability. The developed GAAR serves as an alternative mechanism in teaching and learning human gross anatomy. The real implementation on the feasibility for the infrastructure and to evaluate errors in the model (human organ) and overall "lookand-feel" of the application is depending upon the feedback of future users of GAAR. This initiative aims to fulfill the successful run of operating scenarios of use as well as user satisfaction. The rest section of the study is organized as follows: Section 2 reviews on the related works and tools used for modeling and AR, Section 3 discusses on the methodology undertaken, Section 4 illustrates the experimentation of GAAR. Discussion is outlined in Section 5 and Section 6 summarizes the conclusion and future work of GAAR. 


\section{RELATED WORKS}

\section{A. Reviews of AR Apps}

Teaching and learning demands for a best-fit approach for a sustainable long-life learning environment [1]. Especially in Medical Schools [2], medication practitioners practice the use of recorded videos [3] and podcasts [4] for virtual learning and during the online learning process [5]. The traditional method for an anatomy curriculum during 1980s demands for an improvements [6] and many technological advances in educational sectors has been proposed with the introduction of innovations such as virtual anatomy courses and dissections [7], three-dimensional (3D) atlas as initiated in [8] and "mARble" application that embeds augmented reality (AR) feature for iPhone users [9]. The use of AR applications in medical empower each user experiences and describes the appearance of a digital element generated with a computer [10]. The AR generates a fascinating output since the user can see in 360 angle degree from the human body until its anatomy [11]. Besides, an application that uses AR which called ROAR Augmented Reality created by Roar Interactive on 13 March 2016. BARETA [12] is an AR tool that combines AR and 3D modeling objects to provide simulation for touching as well as sighting.

As reported in School of Medicine of the Aristotle University of Thessaloniki, Greece, indicates the educational innovations in for teaching anatomy is being stigmatized with Andrea Vesalius paradigm [13]. This could be the facts towards dissection in anatomy. The actual intention of AR is not to replace anatomy dissection activity, but it tries to offer the alternative efforts to supplement the traditional curriculum [14-15]. Wikitude for instance, is coupled with its SDK7 that includes simultaneous localizing and mapping for recognition and tracking in 3D objects, image recognizing and tracking, cloud recognition, location-based services, smart glasses as well as external plugin integration in Unity [16].

\section{B. Reviews of AR Platforms}

1) Android OS: The Android Operating System is meant for the mobile device platform that underlies the Linux kernel. It was initiated by Open Handset Alliance on November 2007 using Java programming language [17]. Android is dedicated for open expansion platform where it offers upgrades across various versions. When Android starts releasing its source code, anyone can change it according to individual interests. The project uses the Android Software Developer Kit (SDK), that comes together with the tools and APIs. We integrate the SDK into a graphical user IDE (Integrated Development Environment). The novice can also use App Inventor application to develop an Android-based applications that can be browsed through online.

2) iOS: The iOS is Apple-mobile operating system (OS) for any Apple-manufactured devices includes Apple iPhone, Apple iPad, Apple iPod Touch and Apple TV. These products are popular with the niche style of identity recognition by gestures for instance the gestures to swipe, tap and also pinch. These gestures movement are performed on multi-touch capacities on screen touching displays that provides instant response actions and identify the fingers and pen that act as input.

\section{Reviews of AR SDK}

1) Vuforia: Vuforia is an augmented reality software development kit (SDK) that has been developed for mobile devices. It enables the creation of augmented reality applications. It uses computer vision technology to recognize and track planar images and $3 \mathrm{D}$ objects in real time. Vuforia acts as the first batch of AR environment for an AR application development that comes with a broad set of features. The Vuforia SDK for AR features comprises of a multi-objects recognition for objects like cylinders and boxes as well as the $3 \mathrm{D}$ objects like images, recognition for text of approximately 100,000 words in its vocabulary, the ability to customize the VuMarks, some form of high quality objects than any typical QR-code, feature for 3D geometric map of any environment using Smart terrain, feature to turn static image into full motion video, feature for Unity Plugin and lastly support for cloud and local storage. The Vuforia is supported in iOS, Android, Universal Window Pattern and Unity.

2) ARToolkit: An open-ended source tool for developing an AR application. Equipped with rich set of features for tracking, which include Unity $3 D$ and OpenSceneGraph that includes the facility for both single and dual camera, an apps with featuring object based on location such as GPS and compass support. Also added with the feature to create realtime AR Application, can be integrated with smart glasses, support for multiple language and automatic camera calibration. The ARToolkit supports for Android, iOS, Linux, Window, Mac OS and Smart Glasses and since it is an open source, it is free to use.

3) Wikitude: Wikitude and its SDK7 are included for parallel localizing and mapping. Offers for 3D image recognizing and tracking, recognized within cloud environment with location-based services and integrated with smart glasses and external plugins include Unity. The Wikitude is supported in Android, iOS and smart glasses platform.

The main scope of this article is to describe and demonstrate that development of a free educational mobile application that, with the use of AR, could also help teacher and students interact with each other and provide the user with basic anatomical knowledge for the human internal organs and skeleton system. The breakthrough aim of this application is to introduce the new technological techniques and tools that may reinforces and embarks Malaysia education processes when involving anatomy subject in primary or secondary schools.

\section{MethodOLOGY}

The research methodology is depicted in Fig. 1. There are four phases i.e. Phase 1: Creation of 3D Models, Phase 2: Development of Augmented Reality (AR), Phase 3: Combination of 3D Models and AR and final phase, Phase 4: Development of GAAR Mobile Apps. 


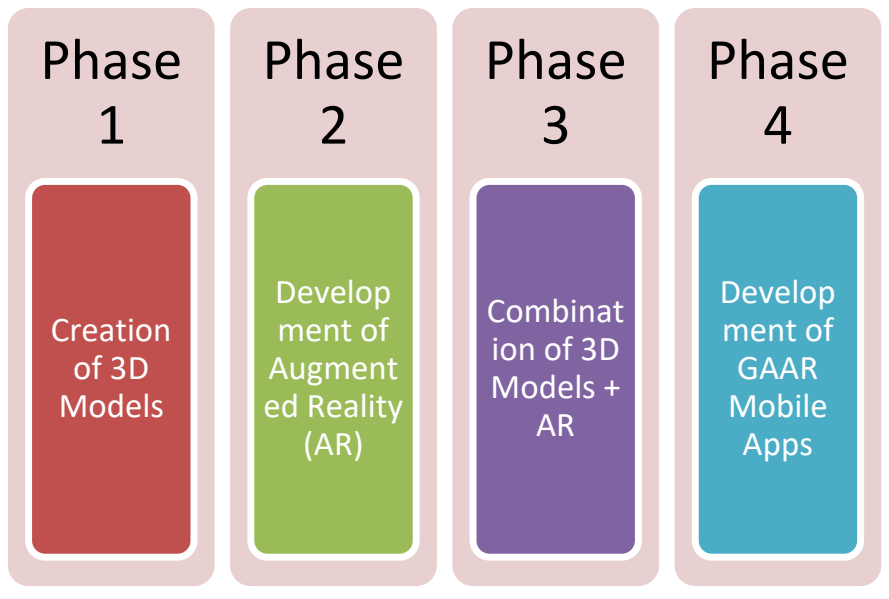

Fig. 1. GAAR Methodology.

To embark the teaching and learning approach with interactivity, the conceptual model of GAAR is outlined as in Fig. 2. The AR technology is to bridge the gap between the real-world surroundings (physical area) and the digital area. The teaching and learning activities are done with interactivities via a tool where there is only need to scan and doing anatomy exercises and see references from the resources provided in GAAR library. The specific content of GAAR is shown in Fig. 3. The traditional textbooks such as Nota Sains Sukan Tahap 1, Skim Persijilan Kejurulatihan Kebangsaan (SPKK) [18] and Augmented Reality for the Study of Human Heart Anatomy [19] are used to evaluate the 3D model of human anatomy such as heart, lung, kidney, human skeleton and liver to design for GAAR content structure.

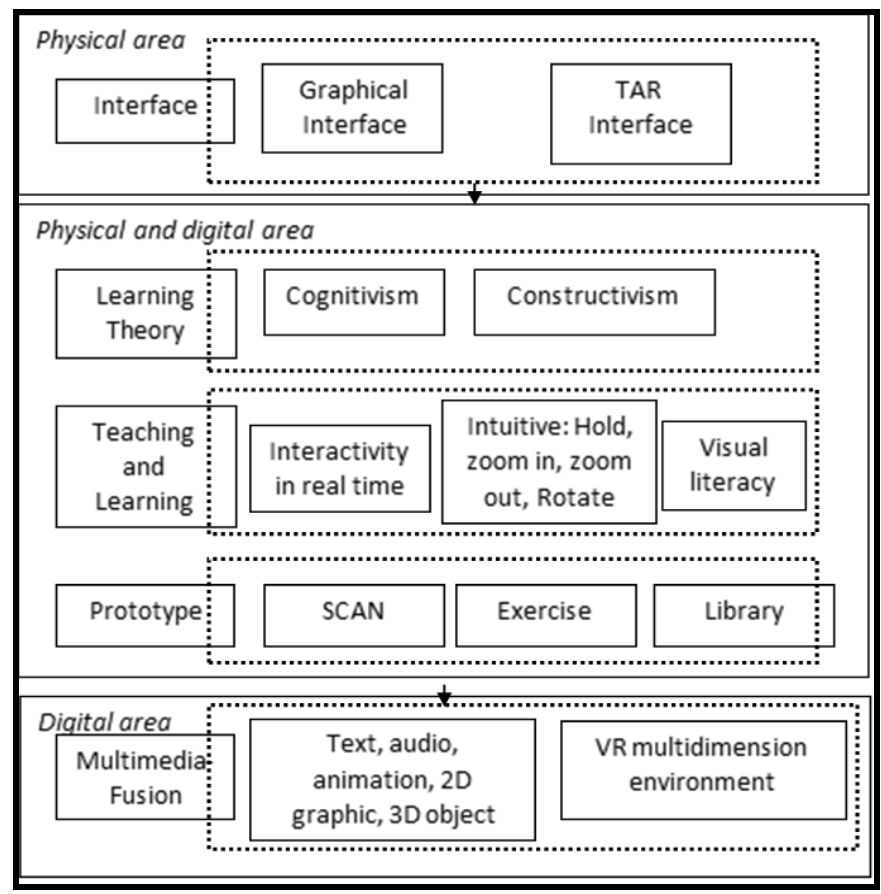

Fig. 2. GAAR Conceptual Model.

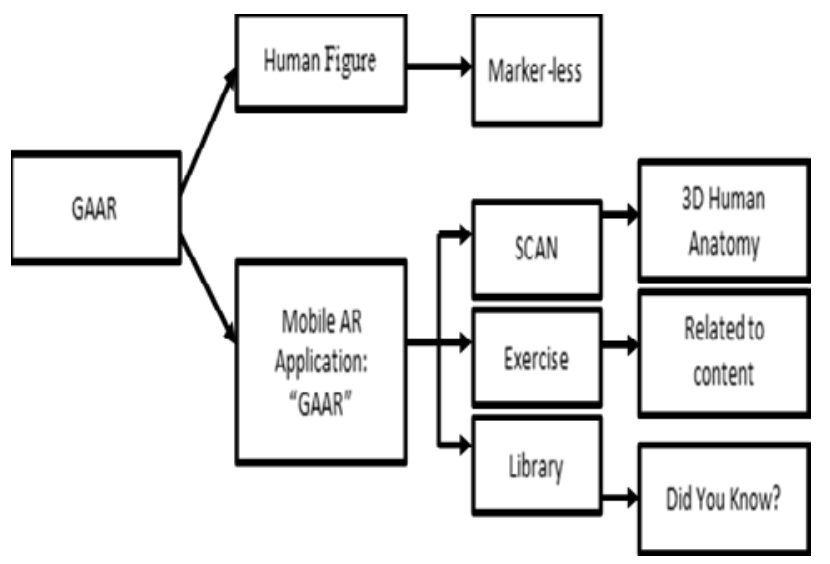

Fig. 3. GAAR Content Structure.

\section{EXPERIMENTATION}

\section{A. Development}

The interactive AR mobile application is only for Android mobile platform use only. Many external code libraries were used: Wikitude SDK, Android SDK, for the 3D models and the Autodesk Maya program for a 3D modelling and animation software. C\# programming is used for creating mobile application using Unity3D. The GAAR mobile application used the concept of marker-less which mean that this mobile application does not required any medium or special paper to interact as marker. The only requirement for GAAR mobile application to work functionally need mobile phone with camera, android version 7.0 above and a flat surrounding to display the models. Using English language, the main menu of the mobile application is divided in seven categories i.e. Book Section, Quiz Game, Anatomy AR, About App, Option, Guide, Exit App. The main features which crucial for GAAR implementation which are anatomy AR, book anatomy and quiz game about anatomy to allow for better understanding about the structure of human skeleton and several main organs including their main function which suitable for young students to understands more about human science anatomy by providing 3D model which resemble to the actual organ and skeleton. Follows are the steps taken during development in Phase 1 of GAAR methodology.

Step 1: choose the correct marker-less Wikitude SDK for Unity as in Fig. 4.

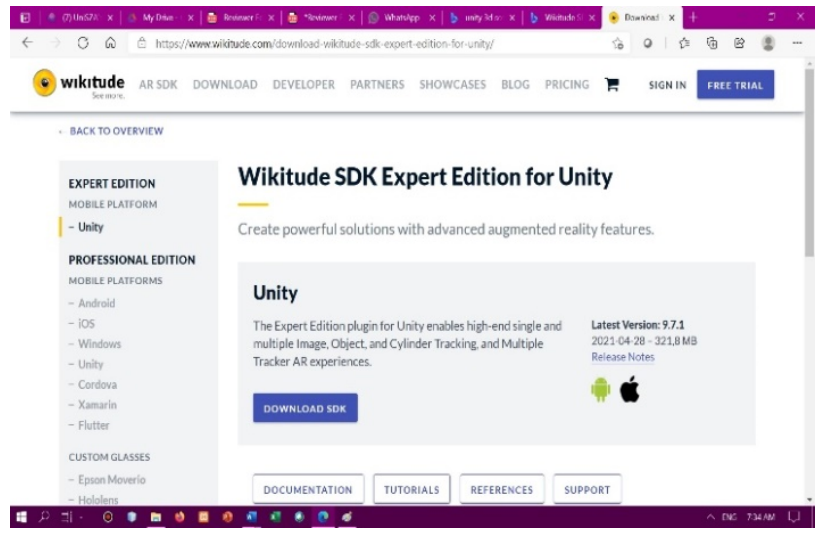

Fig. 4. Choosing Marker-less Wikitude SDK. 
Step 2: 3D modeling of human body using Autodesk Maya as in Fig. 5.

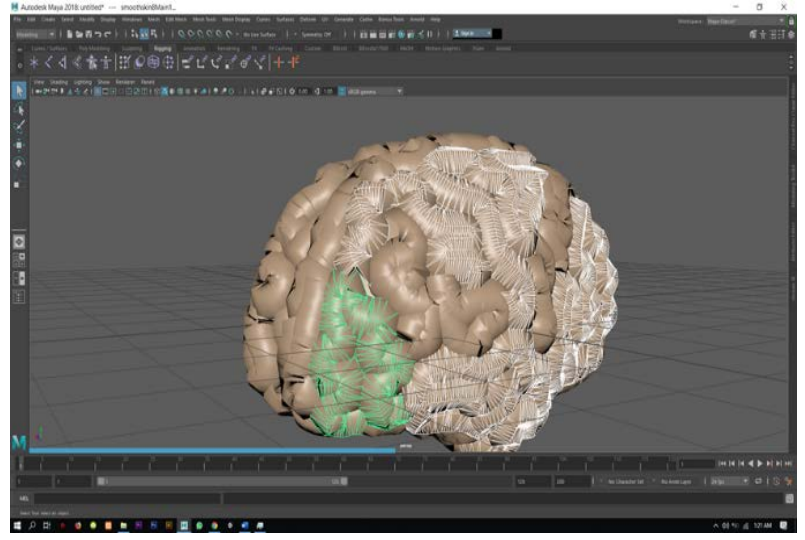

Fig. 5. Modelling in 3D.

Step 3: 3D model texturing in Autodesk Maya. Texturing is a process of making the surface model to look like real-world counterpart as in Fig. 6.

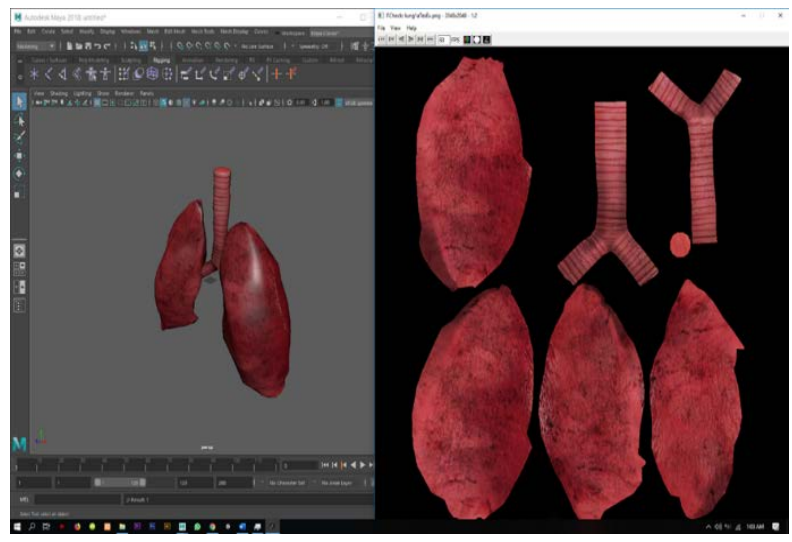

Fig. 6. Texturing.

Step 4: 3D model can be animated by rigging on a character as in Fig. 7. Rigging or skeletal animation means taking a static mesh to create an internal digital skeleton, and creating relationships between the mesh and the skeleton. This process also called as skinning, enveloping or binding process and adding a set of controls that the animator can use to push and pull the character around.

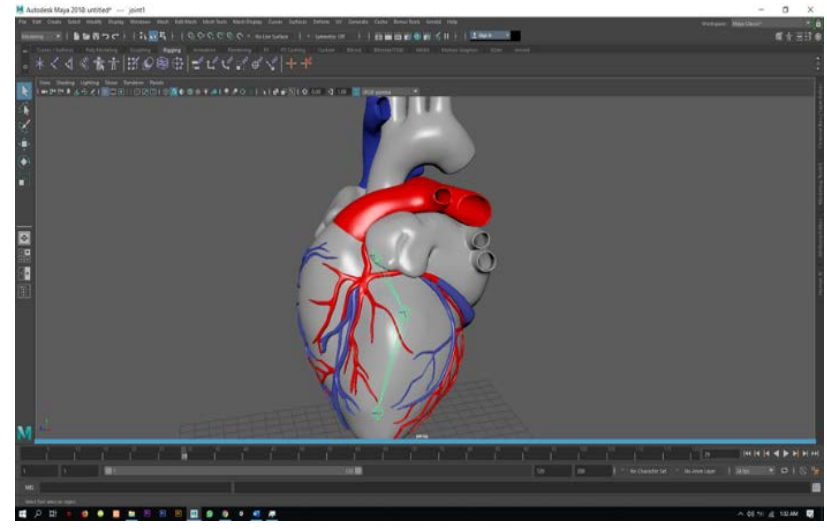

Fig. 7. Rigging.
Step 5: Building 3D model of human counterpart by importing into Unity3D software as in Fig. 8.

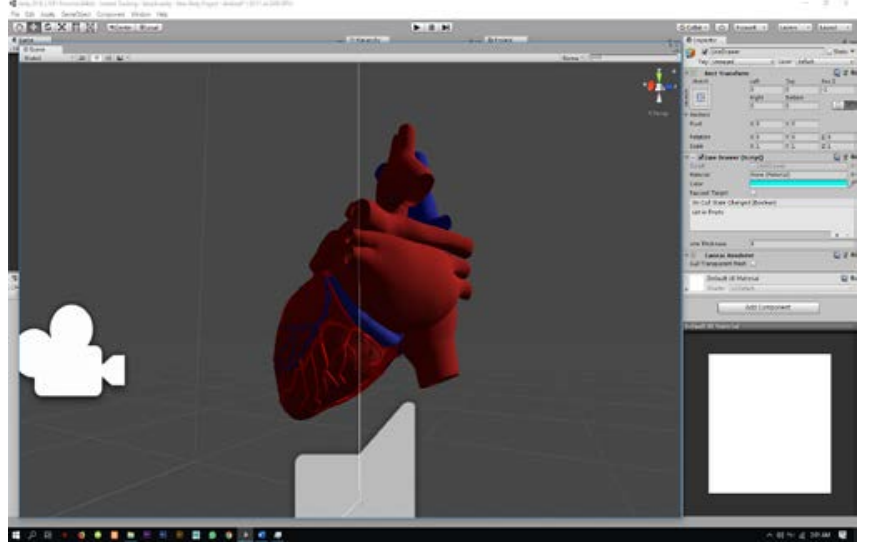

Fig. 8. Building 3D Model into Unity 3D.

Phase 2 is the programming or GAAR while Phase 3 is the combination of 3D models with AR where the apk files are created. Then in the last phase, the coding and programming are performed for GAAR mobile application.

\section{B. Interfaces}

Fig. 9 shows the home menu of the GAAR mobile application. When user first using the application, they will go to this home menu which consists seven buttons for user to explore. Fig. 10 shows the guide button feature. When user click on this button, they show the guide on what do each button state. As such, user can see which button that they need to know and be notify in early stage. These buttons guide with the symbol of boy reading manual, book section with the book symbol, quiz game with the symbol star. The middle button which is called Anatomy AR button which contain eight model of anatomy. The next three buttons is about application, option button and exit button.

Fig. 11 indicates the book section which contains seven buttons that indicated the several information about heart, lung, kidney, stomach, brain, liver and skeleton. Some model such as heart and lung have been provided with sound and animations. All the button give user the 3D model of anatomy and produce four main information about each button that suitable for young students and children. On the top, we have two button which are home button and Anatomy AR button. For the main part of GAAR mobile application is Anatomy AR button. Fig. 12 illustrates the interface of Anatomy AR. In this figure, the interface provides an information for start-up button which is used to explain the step that user needs to know before using Gross Anatomy AR. Then, once clicking on the initialize button, user will be directed with eight different icons which represent the 3D model organs. The GAAR contains eight different 3d models which are heart with animation, lung with animation, skeleton system, liver, kidney, brain, stomach and intestines (refer to Fig. 13). User also be notice with guides when using Anatomy AR as shown in Fig. 14. This small guide informs them on what user should do if user want to zoom, move, and rotate the $3 \mathrm{~d}$ object. If the screen is full of $3 \mathrm{~d}$ models, they can easily reset it all by pressing Reset button above go to Home page. 
In Fig. 15, a 3D skeleton system model is displayed on the screen without any marker. The model also displays the name of bones and description about it. For each model, user have privileges to rotate using arrow provided or zoom by using two finger or move the model to another location. Next is Quiz game as stated in Fig. 16. The GAAR mobile apps provides simple questions which can test user memory based on the information that book section. Based on the figure above, there are nine multiple answer questions. Each question has its own countdown with test user capabilities to answer questions with at short timing. Next button act as submit answer after user pick an answer or not that allows user and audience know either the answer is true or false.

After finish answering those nine questions, the game shows the score and notify them the highest score of the previous challenge. If user want to try again, user can do this by pressing play again button or go to homepage at the home button below high score (see Fig. 17). Fig. 18 shows the graphic and game volume for GAAR mobile application. As for the graphic, it provided user low, medium and high resolution of pictures in the app. Game volume can be adjust either high or low depends on user. Hit apply button to set the options or hit back button to go to home menu. Lastly, the exit button used for user to check out from GAAR mobile application. In the button, it gives user the privilege for user to exit from using the app or stay using it (see Fig. 19).

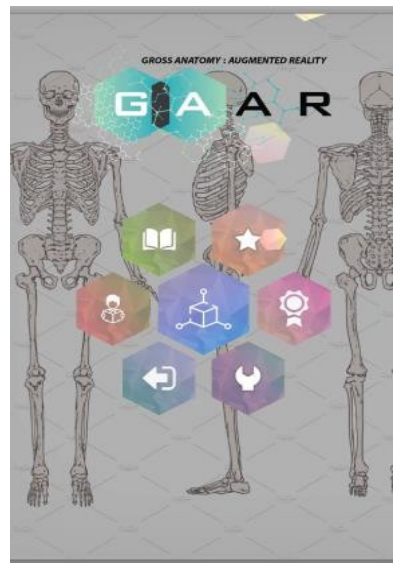

Fig. 9. Main Menu.

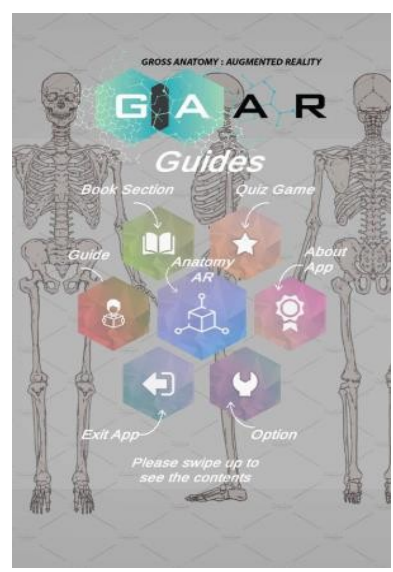

Fig. 10. Guide Buttons.

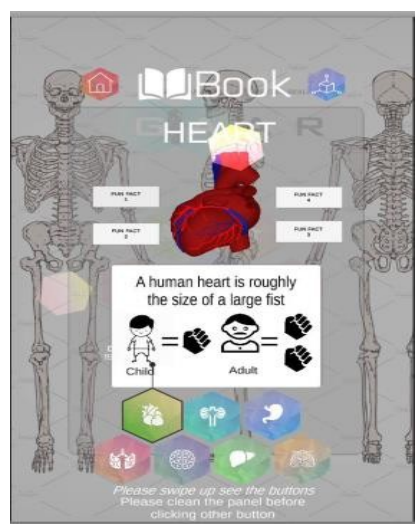

Fig. 11. Book Section.

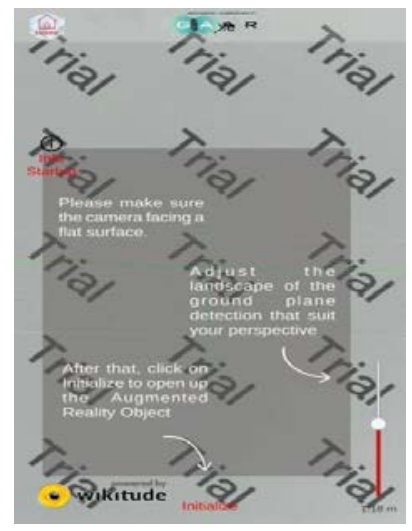

Fig. 12. Guide to use GAAR.

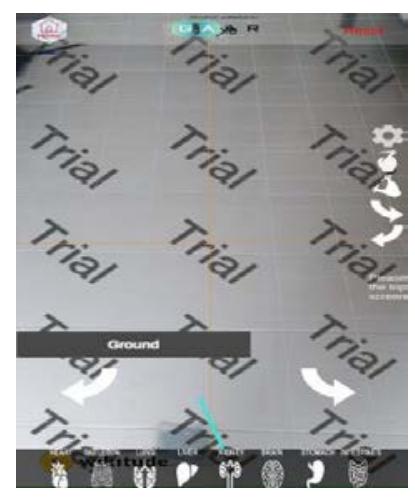

Fig. 13. GAAR Anatomy.

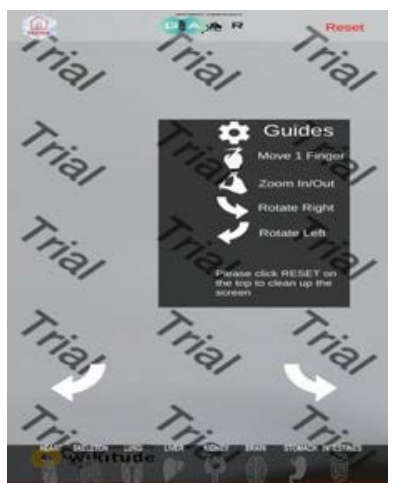

Fig. 14. Guide in Anatomy AR. 


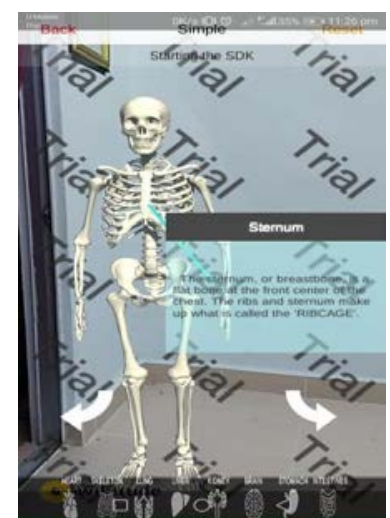

Fig. 15. AR Skeleton.

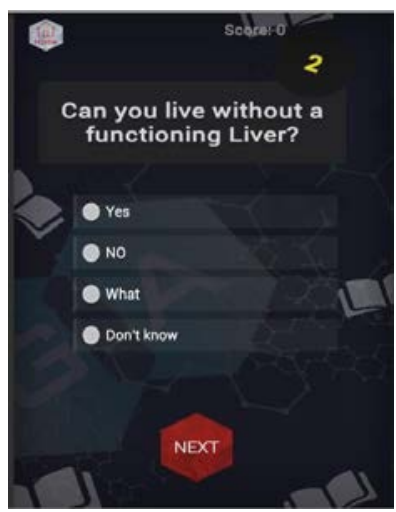

Fig. 16. Quiz and Game Interface.

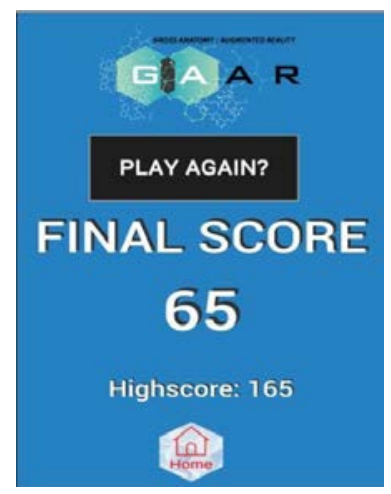

Fig. 17. Score.

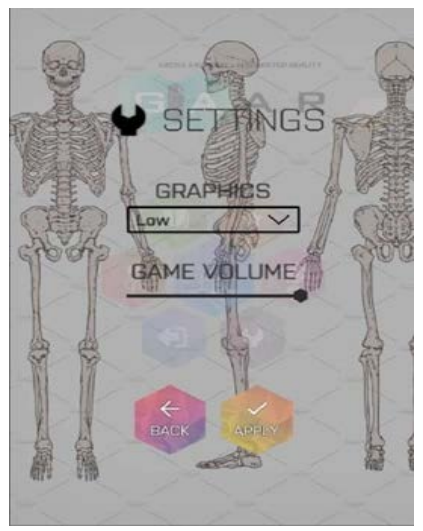

Fig. 18. Setting/Options.

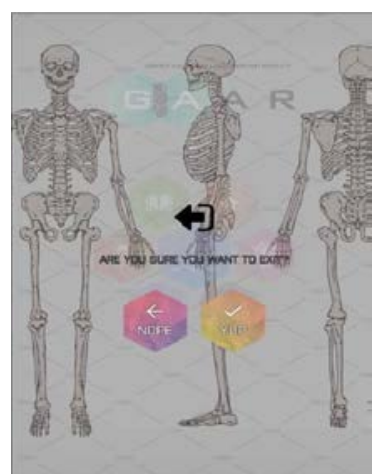

Fig. 19. Exit.

\section{DisCUSSION}

The advantage of a virtual human anatomy is that the gross appearance of the human anatomy drives user to explore for more since user can easily see the model in 360 degree from any angle and observe the shape and where it is located inside a human body. The color, shape, animation and sound give user a real-life experience that they explore human body in reality. Based on the results of our research an interactive mobile application can be created to supplement the traditional descriptive course. This form of application has the advantage that the student can access it from home. Factors such as the resolution of the camera, or the mobile phone have an impact on the in full color appearance but they do not cause deformation of the virtual object.

\section{CONCLUSION AND FUtURE RECOMMENDATIONS}

With this application, the medical lectures, laboratory exercises and the anatomical models, the targets of medical curriculum are accomplished. Because anatomical models and academic lessons is tough to study by oneself, perhaps with GAAR, they are capable of using their own mobile device to interact with 3D model. This GAAR is a mechanism to build interest in human anatomy with immersion. There are a few suggestions that can be used to upgrade GAAR mobile application to be more efficient in future. Our recommendation is to use a paid license version of Wikitude SDK to get rid of the trial watermark in AR camera. Others would be to add more sound to give impact to user when using the application when studying, to improve with a consistent layout of each scene in GAAR mobile app to make it more appeal to user experience, to add more games or interesting activities that can increase user understanding and allow them to memorize the info through game and fun activity. Also, this GAAR could provide more unusual and unseen info but remains a crucial fact about human internal and external body.

The use of AR in education is regards to bridge the digital divide and to provide the static pictures into real-like 3D animation. Through the real visualization, small to adult learners can imitate the real truth on human organ and how this can motivate them to take care of their bodies that would lead to a healthier living styles as well as easy memorizing of the subject contents [20-21]. The GAAR is a mobile application that is useful for all generations of students as well as teachers which give more interactions to explore human body by using smartphone in real environment. Student does not need to 
understand something about human anatomy since they can now use the current textbook and explore it using GAAR. This not only help students to increase their knowledge but also help teacher explain more about human anatomy in their science subject. It is anticipated that by using GAAR, young student can achieve more knowledge and see much more than just using textbook only.

\section{ACKNOWLEDGMENT}

A special thanks to the financial support under UMT Grant with Vot: 53290 and UniSZA grant with code UniSZA/2018/PKP/01 (An intelligent mosquito home system). A sincere gratitude goes to the AMHS co-founder, One Team Network Sdn. Bhd. and Dr. Mos Healthcare Sdn. Bhd. for the idea creation and all faculty members in supporting our work.

\section{REFERENCES}

[1] F. S. Motlagh \& J. A. Pour, "Designing a model for developing students' needs skills of high schools for using virtual learning,” International Journal of Electronics Communication and Computer Engineering, 2014, 3(6), pp. 1444-1448.

[2] S. Standring, Gray's anatomy: the anatomical basis of clinical practice, expert consult (4st Ed). Spain: Churchill Livingstone, 2008.

[3] K. Romanov \& A. Nevgi, "Do medical students watch video clips in eLearning and do these facilitate learning?," Med Teach, 2007, vol. 29, pp. 484-488.

[4] S. Shantikumar, "From lecture theatre to portable media: students' perceptions of an enhanced podcast for revision,” Med Teach, 2009, 31, pp. 535-538.

[5] D. A. Back, N. Haberstroh, A. Antolic, K. Sostmann, G. Schmidmaier \& E. Hoff, "Blended learning approach improves teaching in a problembased learning environment in orthopedics - a pilot study,” BMC Medical Education, 2014, 14, pp.17.

[6] M. A. Aziz, J. C. McKenzie, J. S. Wilson, R. J. Cowie, S. A. Ayeni \& B. K. Dunn, "The human cadaver in the age of biomedical informatics," Anat Rec (New Anat), 2002, 269, pp. 20-32.

[7] H. Petersson, D. Sinkvist, C. Wang \& O. Smedby, "Web-based interactive 3D visualization as a tool for improved anatomy Learning," Anat Sci Ed, 2009, 2, pp. 61-8.

[8] J. Li, L. Nie, Z. Li, L. Lin, L. Tang \& J. Ouyang, "Maximizing modern distribution of complex anatomical spatial information: 3D reconstruction and rapid prototype production of anatomical corrosion casts of human specimens," Anat Sci Ed, 2012, 5, pp. 330-9.

[9] U. Von Jan, C. Noll, M. Behrends \& U. Albrecht, "mARble - augmented reality in medical education,” Biomed Tech 2012, 18, pp. 67-7.

[10] H. Hazidar \& R. Sulaiman, "Visualization cardiac human anatomy using augmented reality mobile application,” IJECCE, 2014, 5(3), pp. 497-501

[11] T. Blum, V. Kleeberger, C. Bichlmeier \& N. Navab, "Mirracle: an augmented reality magic mirror system for anatomy education,” Virtual Reality Short Papers and Posters, 2012, pp. 169-170.

[12] R. Thomas, N. John \& M. Delieu, "Augmented reality for anatomical education,” J Vis Commun Med, 2010, 33, pp. 6-15.

[13] M. Schoonheim, R. Heyden, J.M. Wiecha, "Use of a virtual world computer environment for international distance education: lessons from a pilot project using Second Life,” BMC Medical Education, 2014, 14, pp. 36.

[14] S. B. Issenberg, W. C. McGaghie, E. R. Petrusa, G. D. Lee \& R. J. Scalese, Features and uses of high-fidelity medical simulations that lead to effective learning: a BEME systematic review. Med Teach 2005; 27: pp.10-28.

[15] Z. A. Galchenko,. "Six top tools to build augmented reality mobile apps." Infoq. com Retrieved From: https://www. infoq. com/articles/augmented-reality-best-skds, 2018.

[16] F. Mauro, et al. "Augmented reality as a new media for supporting mobile-learning." Virtual and Augmented Reality: Concepts, Methodologies, Tools, and Applications. IGI Global, 2018, pp.16251643.

[17] K. Iggy, and D. Cummings. "History and Evolution of the Android OS." Android on x86. Apress, Berkeley, CA, 2013, pp. 1-8.

[18] YM Dr. Tengku Fadilah Bt. Tengku Kamalden, 2013, Akademik Kejurulatihan Kebangsaan, Nota Sains Sukan Tahap 1, Skim Persijilan Kejurulatihan Kebangsaan (SPKK).

[19] Kiourexidou, Matina, et al. "Augmented reality for the study of human heart anatomy." International Journal of Electronics Communication and Computer Engineering 6.6 (2015): 658.

[20] D. Schwarz, P. Štourač, M. Komenda, H. Harazim, M. Kosinová, J. Gregor, R. Hůlek, O. Smékalová, I. Křikava, R. Štoudek \& L. Dušek, "Interactive algorithms for teaching and learning acute medicine in the network of medical faculties MEFANET,” J Med Internet Res, 2013, 15(7), pp. e135.

[21] P.E. Antoniou, C.A. Athanasopoulou, E. Dafli, P.D. Bamidis, "Exploring design requirements for repurposing dental virtual patients from the web to second life: a focus group study," J Med Internet Res, 2014, 16(6), pp. e151. 